\title{
High Corrosion Resistance Offered by Carbon Nanotubes Directly Grown over Mild Steel Substrate
}

\author{
Sweety Arora, Rekha M Y, Abhay Gupta and Chandan Srivastava* \\ Department of Materials Engineering, Indian Institute of Science, Bangalore, India. \\ * Corresponding author: csrivastava@materials.iisc.ernet.in
}

Highly hydrophobic nature of carbon nanotubes makes them a promising material for coatings with better corrosion resistance [1,2]. Their application includes using them as a pure coating material [3] or incorporating into the matrix as a reinforcement material [4]. Therefore, several synthesis methods such as laser ablation, electric arc discharge, plasma advanced and chemical vapor deposition have been explored for production of high-quality nanotubes. Of these chemical vapor deposition (CVD) (using nanoparticles as a catalyst) has been proven to produce CNTs at large scale with reasonable quality and lower cost. Most reports that mention carbon-nanotubes based coatings describe the process in two steps, which involves synthesis of nanotubes and dispersing them into a suitable solvent followed by coating it over the substrate [5]. This paper presents a one-step method for directly growing carbon nanotubes over mild steel substrate.

Polished mild steel substrate was placed inside the quartz tube furnace and heated to 800 degrees in argon atmosphere. A constant argon flow rate of $200 \mathrm{sccm}$ was maintained inside the chamber using mass flow controller and a mixture of benzene $(100 \mathrm{ml})$ and ferrocene $(2 \mathrm{~g}$, alfa aesar $99 \%$ pure $)$ was used as a precursor. The precursor solution was poured dropwise into the tube while maintaining a pouring rate of $1 \mathrm{ml} / \mathrm{min}$ manually for 60 minutes. Ferrocene when introduced at 800 degrees, decomposes to form iron nuclei over the substrate while benzene acts as a carbon source leading to carbon nanotube coated surface. ESEM Quanta-200-Scanning electron microscope was used to image the cross-section and the top surface of the coating. A $300 \mathrm{kV}$ field emission FEI TITAN transmission electron microscope was used to image the nanotubes. The electrochemical corrosion study was performed in a conventional glass cell by using CHI 604E electrochemical work station at the room temperature. The multiwalled carbon nanotubes (MWCNTs) coated steel plate, platinum foil and saturated calomel electrode were used as working, auxiliary electrodes and reference electrode respectively. Corrosion studies were performed in $3.5 \mathrm{wt} \%$ $\mathrm{NaCl}$ with $1 \mathrm{~cm}^{2}$ of the working electrode exposed to the media.

The presence of nanotubes was confirmed using Transmission Electron Microscopy. For this, the samples were prepared by first dispersing the scratched coating in hexane and then drop drying it over a carbon coated copper grid. Fig. 1(a) shows low magnification TEM image of the CNTs. Fig. 1(b) represents the SEM image of the aligned CNTs across the cross-section of the coating. The top surface showing uniform bundles of nanotubes as seen in SEM is represented in Fig. 1(c). The contact angles for water droplets over the bare steel substrate and MWCNT-coated substrate were found to be $146^{\circ}$ and $88.68^{\circ}$ respectively. The profiles of the liquid droplets over carbon nanotube coating and bare steel substrate is shown in Fig. 2 The Tafel curves (Fig. 3) for mild steel and CNT coated mild steel were measured at a scan rate of $1 \mathrm{mVs}^{-1}$ by polarizing the electrode to $\pm 200 \mathrm{mV}$ w.r.t the open circuit potential. These Tafel polarization curves were used to obtain the corrosion current ( $\left.\mathrm{I}_{\text {corr }}\right)$, corrosion potential ( $\left.\mathrm{E}_{\text {corr }}\right)$ and corrosion rate $(\mathrm{CR})$ values. The $\mathrm{E}_{\text {corr, }} \mathrm{I}_{\text {corr }}$ and $\mathrm{CR}$ values obtained for mild steel were $-0.595 \mathrm{~V}, 129.8 \mu \mathrm{A}$ $\mathrm{cm}^{-2}$ and 59.2 mils/year respectively. The $\mathrm{E}_{\text {corr }}, \mathrm{I}_{\text {corr }}$ and $\mathrm{CR}$ values obtained for carbon nanotubes coated mild steel were $-0.404 \mathrm{~V}, 35.2 \mu \mathrm{A} \mathrm{cm} \mathrm{cm}^{-2}$ and 16.93 mils/year respectively. The carbon nanotube coated 
specimen exhibited significant shift towards positive values of corrosion potential and a decrease in corrosion current values leading to lesser corrosion rate as compared to bare mild steel specimen. Therefore, it can be concluded that nanotubes coating over a steel substrate enhances its corrosion resistance property.

References:

[1] L Zhang et al., Energy Environ. Sci. 5 (2012), p. 6156.

[2] XH Chen et al., Surf. Coat.Technol. 191 (2005), p. 351.

[3] YB Lee, CH Lee and DS. Lim, Int. J. Hydrogen Energy 34 (2009), p. 9781.

[4] M Park, H Kim and JP Youngblood, Nanotechnology 19 (2008), p. 055705

[5] SR Bakshi et al., Surf. Coat. Technol. 202 (2008), p. 5162.
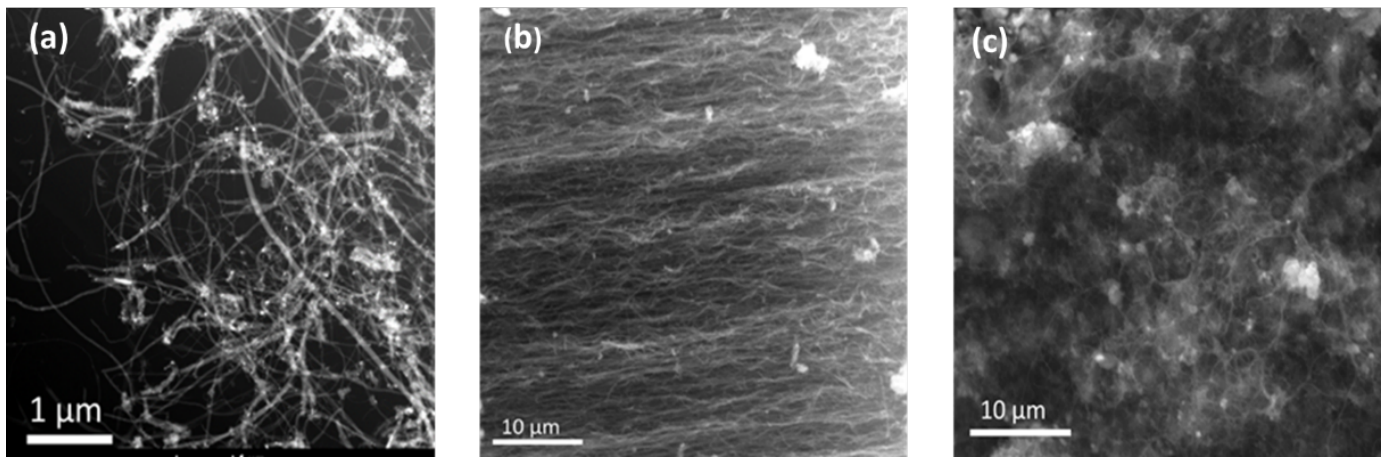

Figure 1. (a)TEM image of MWCNTs; (b) SEM image of coating cross-section; (c) Representative SEM image of MWCNT formed over mild steel substrate (top surface).
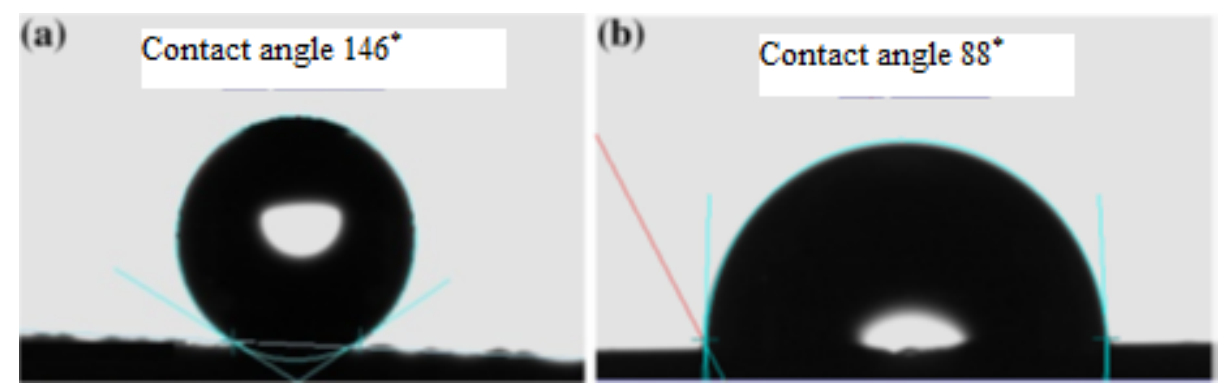

Figure 2. (a) Contact angle measured from the MWCNT-coated steel substrate and (b) the contact angle measured from polished mild steel substrate.

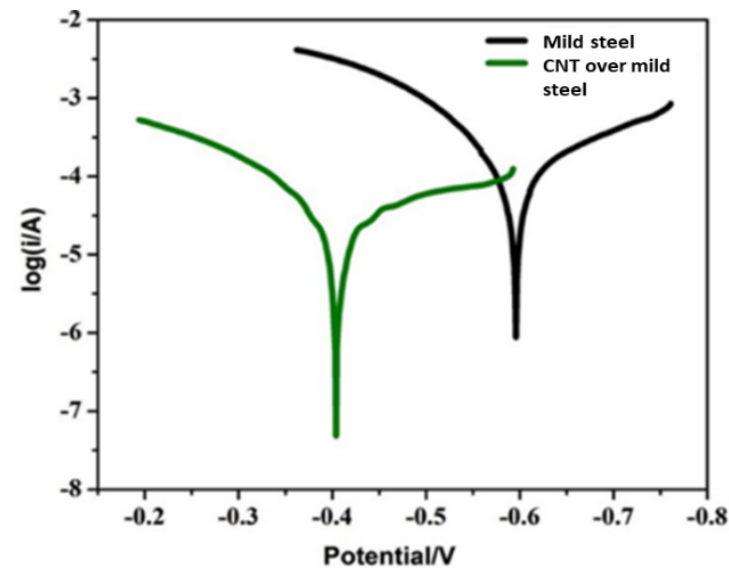

Figure 3. Tafel curves for bare mild steel substrates and coated substrates. 